\title{
The influence of adult conspecifics and shore level on recruitment of the ribbed mussel Geukensia demissa (Dillwyn)
}

\author{
Karina J. Nielsen*, David R. Franz \\ Biology Department, Brooklyn College CUNY, Brooklyn, NY 11210. USA
}

Received 1 June 1994; revision received 2 November 1994; accepted 11 November 1994

\begin{abstract}
The roles of recruitment variability and adult conspecifics on the distribution of Geukensia demissa (Dillwyn) in a Spartina alterniflora (Loisel) marsh were examined in a field study. Recruitment to experimental collectors was compared to recruitment onto the marsh surface at three shore levels. Peak recruitment of mussels in the smallest size class $(0-5 \mathrm{~mm})$ occurred in October. Recruitment was greatest on the marsh edge and to collectors containing adult mussels, suggesting that larval mussels either preferentially settle or have higher survivorship among adult conspecifics. Mussels in the largest size class $(5-15 \mathrm{~mm})$ recruited to collectors in early July suggesting that the previous year's cohort was still actively involved in post-settlement microhabitat selection.
\end{abstract}

Keywords: Geukensia; Intertidal; Recruitment; Ribbed mussel; Salt marsh; Soft bottom

\section{Introduction}

The importance of larval delivery and recruitment in structuring intertidal communities has been the subject of numerous recent investigations, particularly in hard bottom communities (e.g. Grosberg, 1982; Gaines \& Roughgarden, 1985; Gaines et al., 1985; Menge, 1991). However, the role of recruitment in soft bottom communities has not been well studied. Settlement and recruitment may be less important in soft bottom communities because, space is usually not limiting and settlement often does not involve an irreversible commitment (Peterson, 1991). In this paper we experimentally examine the relationship between the recruitment and distribution patterns of a soft

- Corresponding author. Department of Zoology, Oregon State University, Corvallis, OR 97331-2914, LS.4. 
bottom, intertidal dwelling mussel Geukensia demissa (Dillwyn) in a New York salt marsh. Our study demonstrates that although Geukensia may remain actively involved in microhabitat selection for at least a year after settlement, initial recruitment patterns strongly mirror the distribution of the sessile adult population.

Geukensia is an ecologically important and abundant inhabitant of Spartina alterniflora marshes on the Atlantic coast of North America (Kuenzler, 1961a,b; Stiven \& Kuenzler, 1979). Although generally occurring over the entire intertidal zone, most northern Geukensia populations occur in dense aggregations at and near the marsh edge, at middle to low intertidal levels (Bertness \& Grosholz, 1985; pers. obs.). Juvenile mussels are common at the marsh edge but decrease in abundance with tidal height (Bertness \& Grosholz, 1985; unpubl. data). Mussels at the marsh edge grow faster and experience decreased survivorship relative to those at higher intertidal levels (Bertness \& Grosholz, 1985; Stiven \& Gardner, 1992; Franz, 1993). Decreased growth rates at high intertidal levels are attributed to a combination of factors including limited submergence time and filtration of the tidal volume by mussels at the marsh edge (Jordan \& Valiela, 1982; Petersen \& Black, 1987; Franz, 1993). Dense aggregations of filter feeders, like those found on the marsh edge, may also limit recruitment by consuming larvae as they filter the water column (Woodin, 1976). Agents of mortality at the marsh edge include predation by crabs and dislodgment by winter ice (Bertness \& Grosholz, 1985; Hardwick-Witman, 1985; Lin 1990, 1991; Stiven \& Gardner, 1992). However, predation intensity by crabs appears to decrease with increasing latitude and winter ice is only a factor in northern locations. Geukensia's distribution at southern sites (e.g. Alabama and Georgia) is notably different from that found in northern marshes; mussels are more abundant in the high intertidal zone, away from the marsh edge but still aggregated in clumps (West \& Williams, 1986; Lin, 1989). Latitudinal differences in distribution patterns may be attributable to variation in predation and recruitment rates (Menge, 1991).

Bertness \& Grosholz (1985) examined the aggregated distribution of Geukensia in Rhode Island and concluded that mussels $>7 \mathrm{~mm}$ were concentrated at the marsh edge because of "selective settlement", including both larval settlement and post-larval habitat-selection, and that mussels occurring at high intertidal shore levels probably were distributed by factors other than larval recruitment (e.g. rafting of adults in clumps dislodged by winter ice.) They documented a strong inverse relationship between mobility and size, and found that small, mobile mussels traveled an average of $2.1 \mathrm{~cm} /$ day in the field. Our observations of Geukensia in Jamaica Bay indicate that they settle as small as $0.5 \mathrm{~mm}$ in length, thus, the relative importance of initial recruitment patterns and post-settlement movements in determining the distribution of the mature, sessile population remains unclear. We hypothesized that mussels between 0.5 and $7 \mathrm{~mm}$ had the potential to migrate quite far from their initial settlement site. Therefore, teasing apart the relative importance of initial recruitment patterns and post-settlement habitat movements would require frequent observations of the smallest size classes over the recruitment period.

Our field experiment looked at the recruitment pattern of mussels ranging from 0-15 mm from June 1991 through November 1991, at 2-wk intervals. The large number of juvenile mussels that we found among sessile adults at the marsh edge led us to 
hypothesize that recruitment would be greatest within clumps of large mussels regardless of their location within the intertidal zone. We tested this hypothesis by setting out experimental collectors with and without adult mussels at the marsh edge and, two marsh zones that were both higher intertidally and horizontally displaced from the edge.

\section{Materials and methods}

\subsection{Field site}

Field studies were done during the summer of 1991 in the Jamaica Bay Wildlife Refuge (Gateway National Recreation Area), New York. The tidal range at this site is approximately $1.5 \mathrm{~m}$, and the marsh edge was located in the middle intertidal zone $(0.6-0.8 \mathrm{~m})$. The marsh edge was characterized by a near vertical wall up to $25 \mathrm{~cm}$ high composed of densely packed mussels. Immediately behind this edge, the "marsh flat" (following the terminology of Bertness, 1984) graded gradually shoreward and was characterized by "tall" S. alterniflora (Loisel) over a zone about 10 to $20 \mathrm{~m}$ wide. There was no "short" $S$. alterniflora zone, and the narrow $(5-10 \mathrm{~m})$ high marsh band above MHW was chronically disturbed by rafts of Spartina and Phragmites communis Trinius stranded by high tides. The high marsh also lacked $S$. patens (Aiton) Muhl, which is characteristic of this zone in most east coast salt marshes.

\subsection{Recruitment study}

Mussel densities were calculated within three marsh zones: the marsh edge, the marsh flat ( $1.5 \mathrm{~m}$ shoreward, and $\approx 1-5 \mathrm{~cm}$ higher than the edge), and a higher marsh flat location ( $9 \mathrm{~m}$ shoreward, and $\approx 10 \mathrm{~cm}$ higher than the edge); these zones will be referred to as the edge, flat, and high zones, respectively. A transect tape was run parallel to the marsh edge in each zone, a circular quadrat ( $a r e a=346 \mathrm{~cm}^{2}$ ) was randomly placed along the length of the tape, and all mussels within the quadrat were counted ( $n=5$ for the edge, and $n=16$ for both the flat and high zones). This technique probably yields conservative estimates of density as small mussels buried in the sediment may have been missed.

Because juvenile Geukensia are mobile, we assessed recruitment patterns by making frequent observations and focusing on the smallest individuals $(1-15 \mathrm{~mm})$, hereafter referred to as juveniles or recruits. We embedded recruit collectors into the marsh surface and then retrieved and replaced them biweekly from July through November of 1991. The collectors were square plastic flowerpots (sides $7 \mathrm{~cm}$ and $9 \mathrm{~cm}$ deep with drainage holes at the bottom), filled with either adult mussels or marsh sediment. Adult mussels ( $>40 \mathrm{~mm}$ ), were scraped free of all attached organisms, and packed as densely as possible (as in the edge zone) in normal posture (posterior end of the mussel protruding above the top edge of the pot). The mussels placed into the collectors rapidly produced byssal thread, suffered no mortality as a result of being transplanted, and did not migrate out of the collectors. Marsh sediment used to fill collectors consisted of ambient marsh substratum (sand and organic matter) without Spartina or mussels. Ten 
collectors of each substratum type were alternately embedded, at least $20 \mathrm{~cm}$ apart from each other, in a row parallel to the marsh edge in each of the three zones described above. The collectors were retrieved, after remaining $2 \mathrm{wk}$ in the marsh, and the contents searched through under a dissecting microscope in the laboratory. The length and location (i.e. attached to a mussel or the lip of the flowerpot, etc.) of each recruit was noted.

In order to assess the capability of our collectors to reflect recruitment on natural substratum, samples of marsh turf, $15 \mathrm{~cm}$ square, were cut by spade once a month. Size frequency distribution and age structure of mussels from the turf samples were used to confirm the timing and rate of recruitment to each zone. The samples were haphazardly taken from the three marsh zones adjacent (within $20 \mathrm{~m}$ ) to the area with recruit collectors. All mussels were sorted out of the marsh matrix over a $2 \mathrm{~mm}$ sieve.

Mussel age was determined by counting external growth rings following the methods of Lutz \& Castagna (1980) and Brousseau (1984). Annual growth rings appear as dark, thickened rings on the shell surface and, in Jamaica Bay, are produced at the time of new growth in May (Franz \& Tanacredi, 1993.) Brousseau (1984) considers this method of aging accurate with the caveat that age may be under-estimated by $1 \mathrm{yr}$, especially in older valves where significant erosion has occurred around the umbo.

Recruitment data from experimental collectors were analyzed using multiple linear regression (MLR) techniques. Because data were not recorded with reference to specific collector locations within a zone, neither a repeated measures analysis nor, assessment for serial correlation could be made. Although treatment effects can be estimated using MLR with serially correlated data, the standard errors may not be accurate, and thus $p$-values must be interpreted with caution. The independent variables were coded as dichotomous variables yielding the MLR equivalent of an ANOVA (Sokal \& Rohlf, 1981; Tabachnick \& Fidell, 1989). A square root transformation of the data was chosen after visual inspection of residual plots from the MLR to eliminate heteroscedasticity. The MLR was calculated using Statgraphics Statistical Graphics System (version 5.0).

\section{Results}

Mussel density $\left( \pm\right.$ SE) at the marsh edge was $9227( \pm 731) / \mathrm{m}^{2}$ declining sharply to $1635( \pm 30) / \mathrm{m}^{2}$ on the marsh flat, and $397( \pm 15) / \mathrm{m}^{2}$ in the high zone. The density recorded for the marsh edge was almost eight times that reported by Bertness \& Grosholz (1985) for the edge of a Rhode Island marsh at approximately the same tidal height (mean density $=1235 / \mathrm{m}^{2}$ ). The density recorded for the marsh flat was comparable to other sites within Jamaica Bay (Franz \& Tanacredi, 1993) but also higher than that recorded in Rhode Island (Bertness \& Grosholz, 1985).

Recruitment of juvenile mussels to collectors with adult mussels was greater than to marsh sediment alone regardless of zone (Fig. 1; $p<0.0001$, Table 1). Recruitment to collectors with adult mussels in the marsh edge was three times as great as recruitment to either the flat or high zones. Collectors with marsh sediment had less than half the number of recruits as those with adult mussels in both the flat and high zones. No data 
SUBSTRATE PREFERENCE

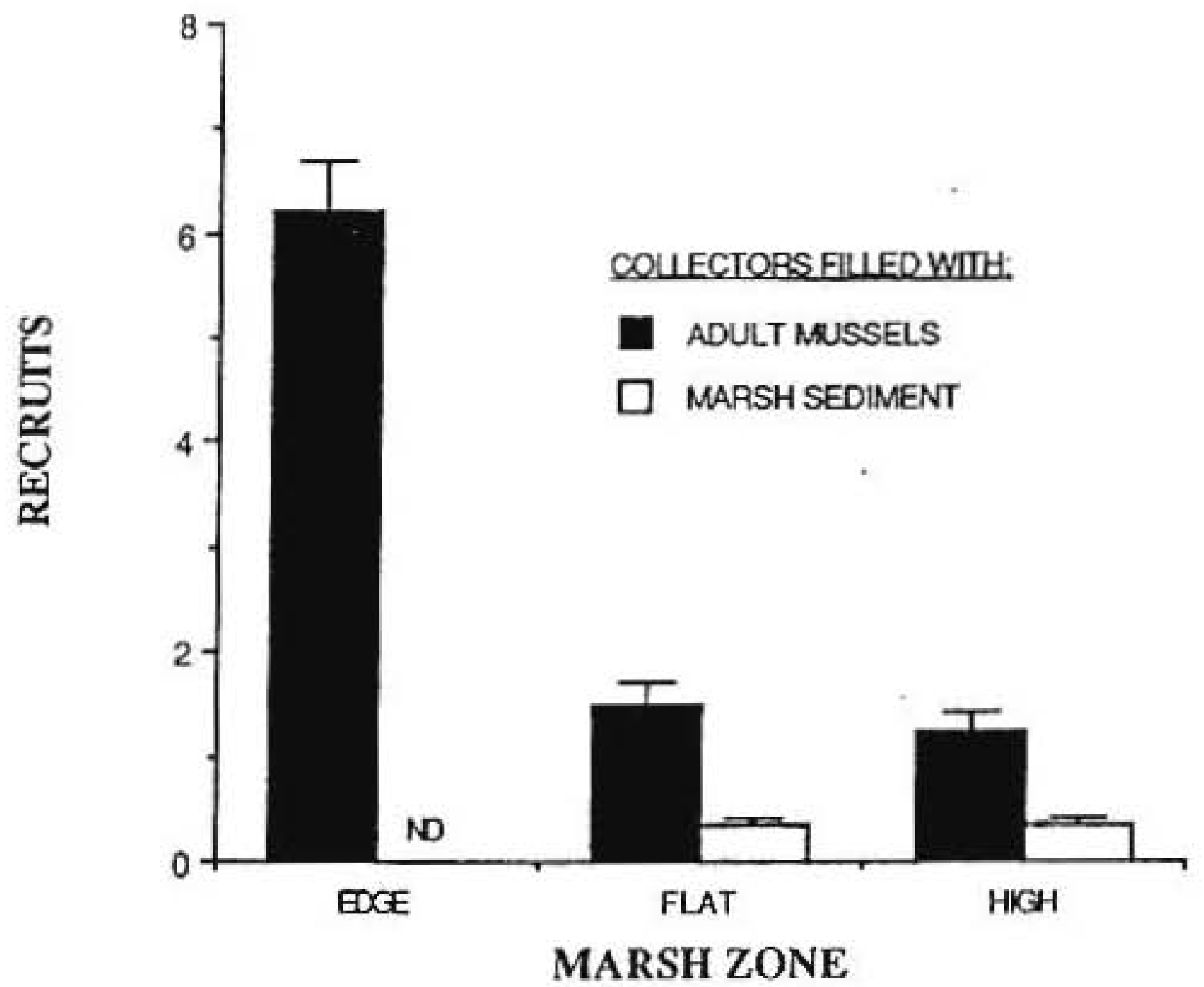

Fig. 1. Mean number of recruits per collector (error bars $=1 \mathrm{SEM}$ ) for each zone. ND $=$ no data collected. Collectors filled with sediment could not be maintained at the marsh edge.

Table 1

Multiple linear regression analysis using dichotomous variables for collector type, marsh zone, and date

\begin{tabular}{lclc}
\hline Variable & Coefficient & Standard error & $p$-value \\
\hline Constant & 1.67 & 0.13 & $<0.0001$ \\
Collector & 0.62 & 0.08 & $<0.0001$ \\
Flat zone & -1.45 & 0.10 & $<0.0001$ \\
High zonc & -1.49 & 0.10 & $<0.0001$ \\
Time 2 & 0.05 & 0.13 & 0.71 \\
Time 3 & 0.07 & 0.13 & 0.57 \\
Time 4 & 0.04 & 0.13 & 0.74 \\
Time 5 & -0.06 & 0.13 & 0.64 \\
Time 6 & 0.42 & 0.13 & 0.0016 \\
Time 7 & 0.02 & 0.13 & 0.86 \\
Time 8 & -0.12 & 0.16 & 0.44 \\
\hline
\end{tabular}

Analysis of variance for the full regression model

\begin{tabular}{llrccc}
\hline & Sum of squares & df & Mean square & $F$-ratio & $p$-value \\
\hline Model & 234.52 & 10 & 23.25 & 50.24 & $<0.00001$ \\
Error & 185.79 & 398 & 0.47 & &
\end{tabular}

Times correspond to collection dates in Fig. 3 (e.g. Time $2=$ August 6, etc.). The adjusted $r^{2}=0.55$ for the regression model. 


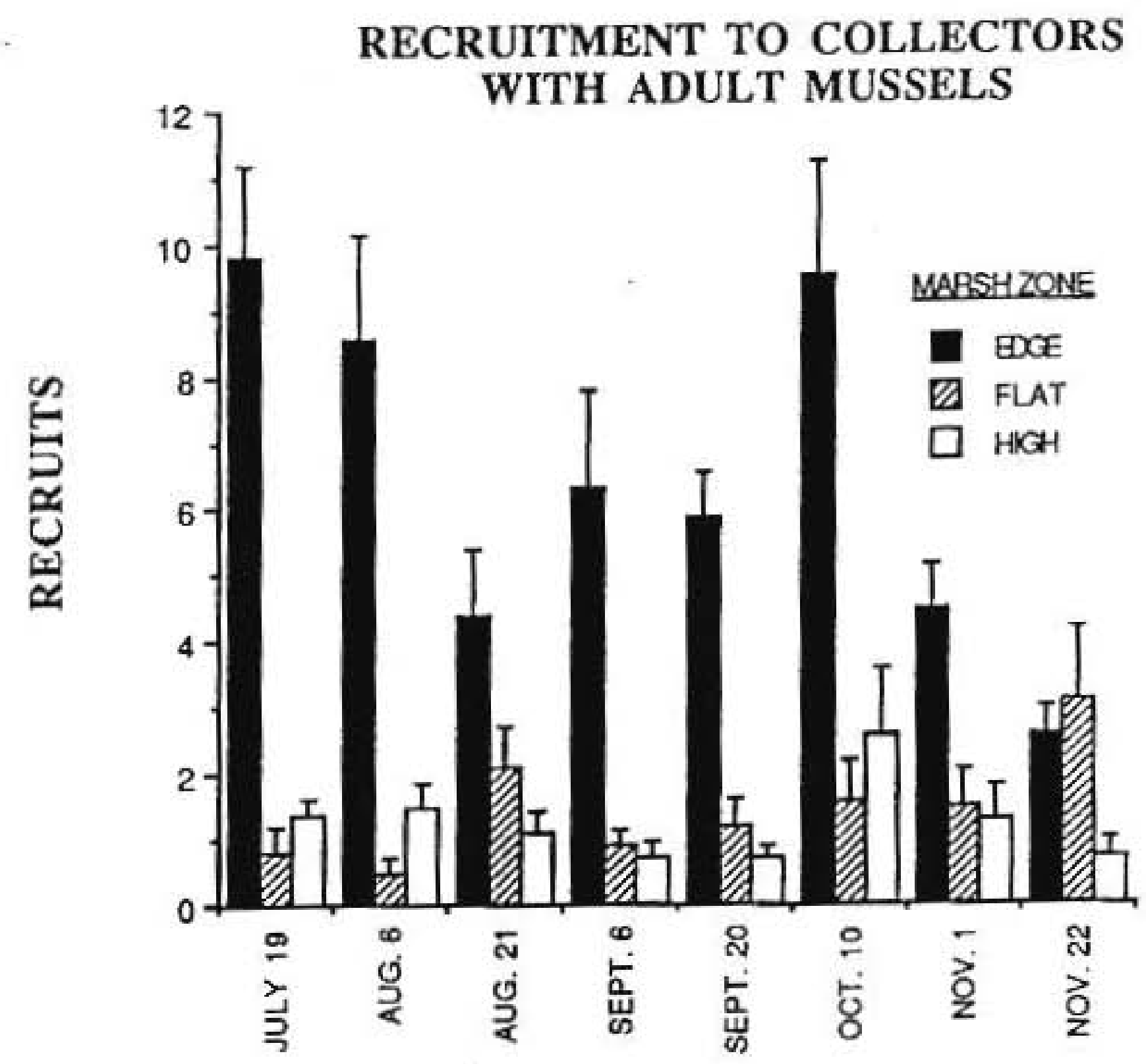

Fig. 2. Temporal recruitment pattern mean number of recruits (error bars $=1$ SEM) from collectors with adult mussels.

RECRUITMENT TO THE MARSH EDGE

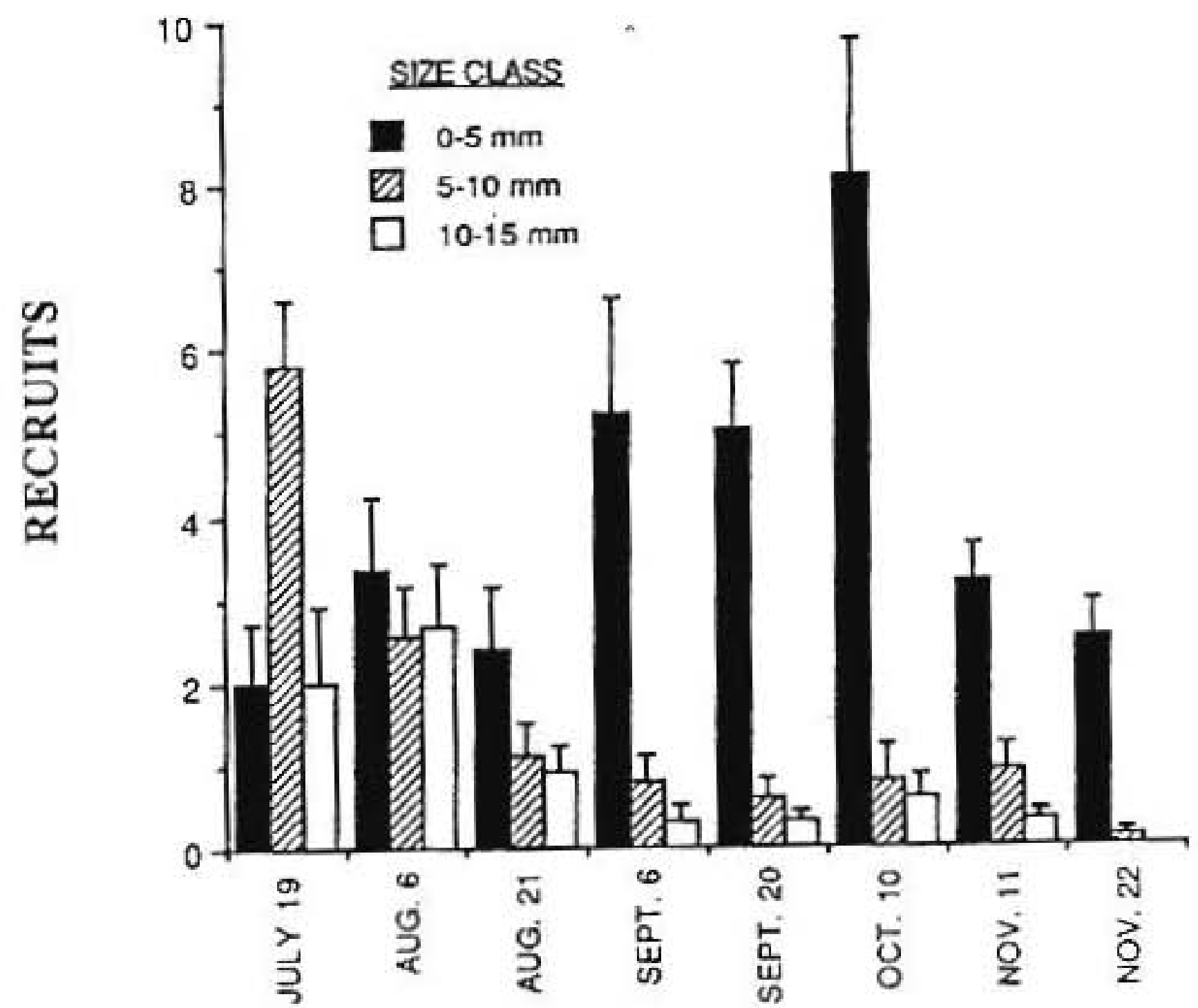

Fig. 3. Patterns of recruitment by size class. Mean number of recruits (error bars $=1$ SEM) from collectors with adult mussels. 
was obtained for collectors with marsh sediment in the marsh edge because the sediment was washed out of the collectors within a few days.

Sixty percent of recruits found in collectors with sediment were located along the lip of the flowerpot and not in the sediment, $18 \%$ were attached to large mussels that migrated into the collectors (this occurred very infrequently but recruits were often found "hitchhiking"), $14 \%$ were found on algae (usually Ulva), and only $8 \%$ were found in the sediment. Sixty-two percent of recruits found in collectors with adult mussels

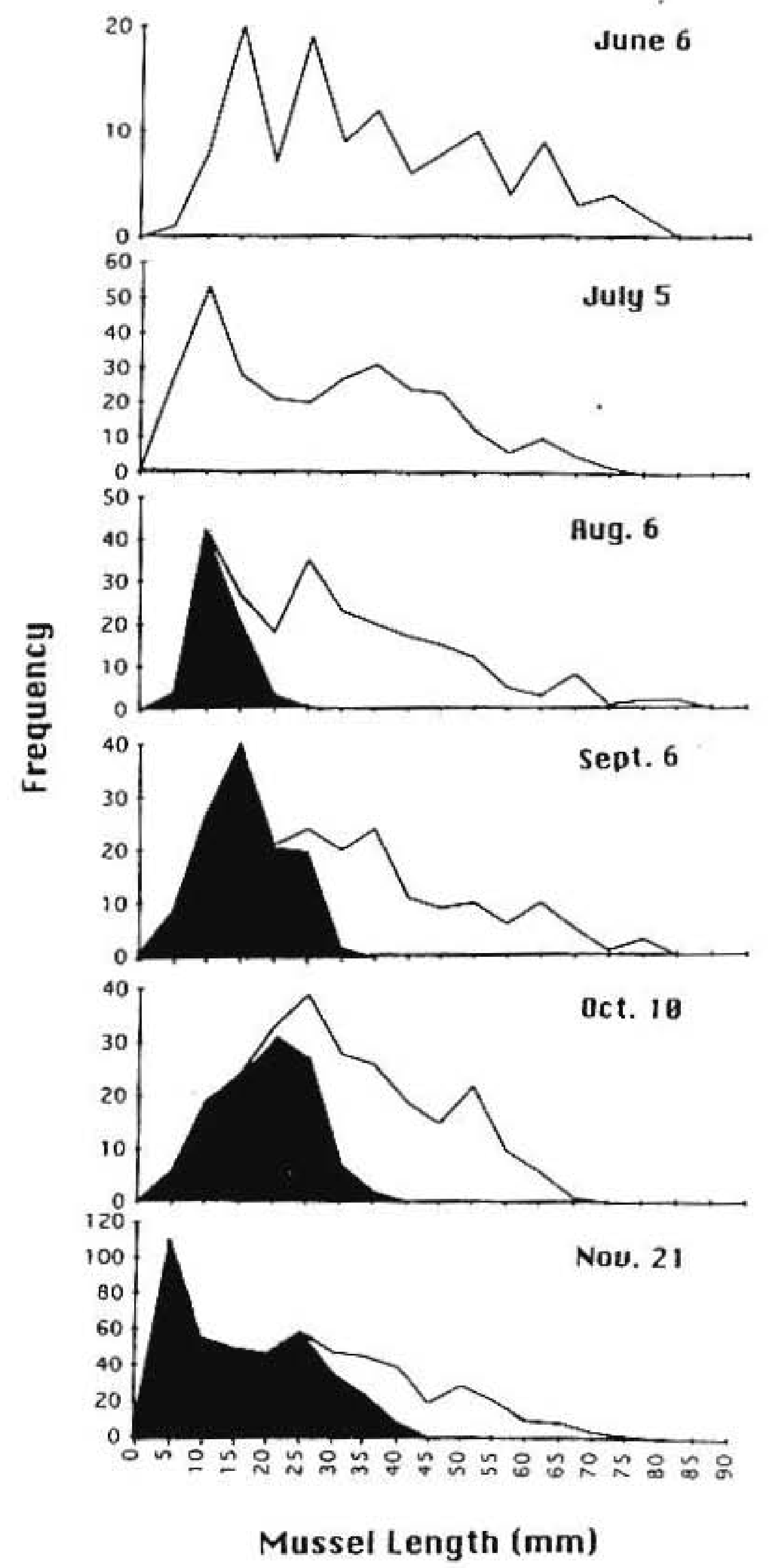

Fig. 4. Size frequency distributions of mussels from monthly turf samples. The darkened area is the size frequency of the current year's recruits. 
were attached to those mussels, $34 \%$ were attached to the lip of the flowerpot, $3 \%$ attached to algae, and $1 \%$ were in sediment that had accumulated in the pots.

Two peaks in recruitment onto the marsh edge occurred on July 19 and October 10 (Fig. 2). However, over all treatments and zones the only significant peak in recruitment indicated by the MLR was on October $10(p=0.0016$, Table 1). Fig. 3 shows the pattern of recruitment to the marsh edge for three size classes. The smallest recruits $(0-5 \mathrm{~mm})$ peak in abundance only on October 10 . On July 19 the peak is primarily composed of mussels larger than $5 \mathrm{~mm}$ and most of these mussels had a dark pigment band resembling a growth annulus that was absent from recruits found later in the season. Personal observations indicated that these dark pigment bands were formed during the winter months, indicating these mussels had settled on to the marsh the previous year. The age and size frequency data from turf samples taken from the marsh edge show that while recruits began to appear in August the highest frequency of small mussels did not occur until November (Fig. 4). Recruits from turf samples were identified by the absence of a growth ring. The age and size frequency data from the high and flat zones showed no distinct peak in recruitment; but the frequency of recruits was consistently lower than from the edge zone.

Recruit densities were calculated from the cumulative number of recruits found in collectors with adult mussels, and the final turf sample taken in November 1991. Densities for the edge zone from collectors and turf samples were comparable $\left(6643 / \mathrm{m}^{2}\right.$ from turf samples and $6891 / \mathrm{m}^{2}$ from collectors). However, the density of recruits in collectors exceeded that from turf samples from both the flat and high zones $\left(639 / \mathrm{m}^{2}\right.$ from turf and $2174 / \mathrm{m}^{2}$ from collectors in the flat zone, and $167 / \mathrm{m}^{2}$ from turf and $1739 / \mathrm{m}^{2}$ from collectors in the high zone).

\section{Discussion}

Our data suggest that adult distribution patterns for Geukensia were strongly influenced by the pattern of recruitment. The movement of $5-10 \mathrm{~mm}$ mussels into collectors in July before the main recruitment pulse supports the findings of Bertness \& Grosholz (1985) that small, post-larval juveniles participate in microhabitat selection, in effect a kind of "secondary settlement". These small, mobile mussels were probably members of the previous year's cohort (1990-class), as indicated by the occurrence of a single growth interruption annulus, or the presence of dark pigment bands characteristic of very small over wintering mussels (pers. obs.). Furthermore, since in this region Geukensia spawns during mid to late summer (Brousseau, 1982; pers. obs.) it is unlikely that small mussels found in June (and throughout the winter and spring are new recruits. The time from fertilization to metamorphosis of laboratory reared Geukensia is about one month (Loosanoff \& Davis, 1963), which is in rough agreement with the observed time from probable spawning to recruitment in the present study.

We found that tidal coverage alone did not explain the distribution of recruits, even though it was positively correlated with recruitment rates. When adult mussels were encountered at higher zones they significantly increased recruitment over what was expected considering tidal coverage alone. This suggests that chemical and/or tactile 
cues associated with adult conspecifics may promote settlement. Recruitment does not appear to be limited by adult filtration and ingestion of larvae as suggested by Woodin (1976). It is possible that filtration and then subsequent deposition of these larvae together with pseudofeces by adults may actually enhance settlement to mussel beds.

Gregarious settlement may be a mechanism for maximizing the probability of recruiting to the marsh edge, where growth conditions are most favorable. However, the dense band of mussels at the edge, enhanced over time by selective recruitment, may further depress food resources for those mussels at higher zones. At higher shore levels settling among adults may still confer advantages to a juvenile mussel by providing crevices that may aid in escaping predation or reducing desíccation and thermal stress, and providing a solid substratum to attach to thus avoiding sediment burial.

Greater recruitment to collectors at high shore levels in comparison to turf samples was probably the result of the higher density of mussels found in experimental collectors compared to the natural density of mussels in the high marsh zone. An alternate explanation is that juvenile mussels in turf samples experienced greater mortality than those in recruit collectors. Although mortality of adults appears to be lower at higher shore levels (Bertness \& Grosholz, 1985), mortality of recruits at the time of, and shortly after, settlement has not been determined. Although we did not place collectors in the Spartina patens zone (i.e. above $\mathrm{MHW}$ ) it seems likely larvae may settle directly into this zone during extreme high tides, in addition to the "rafting" described by Bertness \& Grosholz (1985).

In spite of the potential for post-settlement dispersal in Geukensia the initial pattern of recruitment appears to have a strong influence on the distribution of this species. Thus, although settlement does not involve an irreversible commitment, it is still important in explaining the distribution pattern of a soft sediment dwelling species. Juvenile mobility seems to be more important on smaller spatial scales, such as microhabitat selection and avoidance of sediment burial, but does not affect the larger scale patterns established during recruitment. The dense band of mussels found at the marsh edge in Jamaica Bay appears to be maintained, at least in part, by a positive interaction between juvenile and adult mussels.

\section{References}

Bertness, M.D., 1984. Ribbed mussels and Spartina altermiftora production in a New England salt marsh. Ecology; Vol. 64, pp. 1794-1807.

Bertness, M.D. \& E. Grosholz, 1985. Population dynamics of the ribbed mussel Geukensia demissa: the costs and benefits of an aggregated distribution. Oecologia, Vol. 67, pp. 192-204.

Brousseau, D.J., 1982. Gametogenisis and spawning in a population of Geukensia demissa from Westport. Connecticut. Veliger, Vol. 24, pp. 247-251.

Brousseau, D.J., 1984. Age and growth rate determination for the Atlantic ribbed musscl Geukensia demissa Dillwyn (Bivalvia: Mytilidae). Estuaries, Vol. 7. pp. 233-241.

Franz, D.R., 1993. Allometry of shell and body weight in relation to shore level in the intertidal bivalue Genkensia demissa (Bivalvia:Mytilidae). J. Exp. Mar. Biol. Ecol. Vol. 174. pp. 193-207.

Franz, D. R. \& Tanacredi. 1993. Variability in growth and age structure among populations of ribbed mussels Geukensia demissa (Dillwyn) (Bivalvia:Mytilidac) in Jamaica Bay, NY (Gateway NRA). Veliger. Vol. 36. pp. $220-227$. 
Gaines, S. \& J. Roughgarden, 1985. Larval settlement rate: a leading determinant of structure in an ecological community of the marine intertidal zone. Proc. Natl. Acad. Sci., Vol. 82, pp. 3707-3711.

Gaines, S., S. Brown \& J. Roughgarden, 1985. Spatial variation in larval concentration as a cause of spatial variation in settlement for the barnacle Balanus glandula. Oecologia, Vol. 67, pp. 267-272.

Grosberg, R.K., 1982. Intertidal zonation of barnacles: the influence of planktonic zonation of larvae on vertical distribution of adults. Ecology, Vol. 63, pp. 894-899.

Hardwick-Witman, M.N., 1985. Biological consequences of ice rafting in a New England salt marsh community. J. Exp. Mar. Biol. Ecol., Vol, 87, pp. 283-298.

Jordan, T.E. \& I. Valiela, 1982. A nitrogen budget for the ribbed mussel Geukensia demissa and its significance in energy flow in a New England salt marsh. Limnol. Oceanogr. Vol. 27, pp. 75-90.

Kuenzler, E.J., 1961a. Structure and energy flow of a mussel population in a Georgia salt marsh. Limnol. Oceanogr., Vol. 6, pp. 191-204.

Kuenzler, E.J., 1961b. Phosphorus budget of a mussel population. Limnol. Oceanogr., Vol. 6, pp. 400415.

Lin, J., 1989. Influence of location in a salt marsh on survivirship of ribbed mussels. Mar. Ecol. Prog. Ser., Vol 56, pp. $105-110$

Lin, J., 1990. Mud crap predation on ribbed mussels in salt marshes. Mar. Biol., Vol. 107, pp. 103-109.

Lin, J., 1991. Predator-prey interactions between blue crabs and ribbed mussels living in clumps. Estuarine Coastal Shelf Sci.. Vol. 32, pp. 61-69.

Loosanoff, V.T. \& H.C. Davis, 1963. Cited in F.C. Daiber, ed., Animals of the tidal marsh. Van Nostrand Reinhold Co., NY, 1982.

Lutz, R.A. \& M. Castagna, 1980. Age composition and growth rate of a mussel (Geukensia demissa) population in a Virginia salt marsh. J. Moll. Stud., Vol. 46, pp. 106-115.

Menge, B.A., 1991. Relative importance of recruitment and other causes of variation in rocky intertidal community structure. J. Exp. Mar. Biol. Ecol., Vol. 146, pp. 69-100.

Peterson, C.H., 1991. Intertidal zonation of marine invertebrates in sand and mud. Am. Sci. , Vol. 79. pp. $236-249$.

Peterson, C.H. \& R. Black, 1987. Resource depletion by active suspension feeders on tidal flats: influence of local density and tidal elevation. Limnol. Oceanogr. 32, pp. 143-166.

Sokal, R.R. \& F.J. Rohlf 1981. Biometry. W.H. Freeman \& Co., New York, second edition.

Stiven, A.E. \& S.A. Gardner, 1992. Population processes in the ribbed mussel Geukensia demissa (Dillwyn) in a North Carolina salt marsh tidal gradient: spatial pattern, predation, growth and mortality. J. Exp. Mar. Biol. Ecol., Vol. 160, pp. 81-102.

Stiven, A.E. \& E.J.Kuenzler, 1979. The response of two salt marsh mollusks, Littorina irrorata and Geukensia demissa, to field manipulations of density and Spartina litter. Ecol. Monogr., Vol. 49, pp. 151-171.

Tabachnick, B.G. \& L.S. Fidell, 1989. Using multivariate statistics, Harper \& Row, New York, second edition.

West, D.L. \& A.H. Williams 1986. Predation by Callinectes sapidus (Rathbun) within Spartina alterniflora (Loisel) marshes. J. Exp. Mar. Ecol. Biol., Vol. 100, pp. 75-95.

Woodin. S.A., 1976. Adult-larval interactions in dense assemblages: patterns of abundance. J. Mar. Res.. Vol. 34, pp.25-41. 